\title{
Integrated management of root knot nematode Meloidogyne incognita Chitwood in mulberry (Morus spp)
}

\author{
N.Vijaya Kumari and P.Sujathamma \\ Dept.of Sericulture,Sri.Padmavathi Mahila Visvavidyalayam(Women's University), Tirupathi,Pin - 517502 \\ Andhra Pradesh, India.
}

\begin{abstract}
Meloidogyne incognita is one of the major disease causing agents of Mulberry. This pathogen causes root knot disease in mulberry which causes 12-25\% yield loss. There are a number of management techniques for the management of nematode but no single method alone can control this problem. So, in the present study an integration of different ecofriendly biocontrol methods were selected to know their efficacy on the management of root knot nematode in different mulberry varieties viz.Tr10, DD,V1RFS175,K2 and MS8. It was found that this integrated nematode management method can control nematode problem up to $83.30 \%$ in Tr10 variety which is highest among the six varieties selected. And the less percentage of reduction and growth of plants was observed in MS8 variety. Highest percentage of growth and yield was observed in Tr10 variety.
\end{abstract}

Key words: Meloidogyneincognita, Verticilliumchlamidosporium, Vesicular Arbuscular mychorrhizae(VAM), Neem cake, Mulberry Yield, Yield loss, Root gall.

\section{Introduction:}

Mulberry, the sole food source of silkworm Bombyx mori is prone to many diseases caused by fungi, bacteria, viruses, mycoplasma and nematodes. These microorganisms are the main obstacles causing considerable loss in yield and nutritive values of mulberry foliage (Chanturia, 1963; Shree etal., 1986; Shree and Umesh kumar, 1991).These diseases cause 10-30\% leaf yield loss reducing the quality. Root knot disease caused by nematode Meloidogyne incognita is a serious one and causes 10-12\% leaf yield loss. These nematodes are the major group of plant parasites and their world wide distribution, extensive host range and involvement in disease complexes with other pathogens make them a serious threat to the world's food supply (Sasser, 1989). Loss due to root knot nematodes in various crops is estimated to be around 11-25\%(Sasser1979).In mulberry these nematodes cause formation of galls/knots on the roots and stunted growth with reduced vigour of the plant (Saha et al., 1985). Mulberry being perennial plant when once nematode get established in the garden it is difficult to eradicate it. This root knot disease is more prevalent in sandy soils under irrigated farming systems and reduces the leaf production causing loss of revenue for mulberry growers (Sharma et al., 1998; Sharma and Sarkar1998).

Any strategy for the management of nematodes depends on the crop life cycle, total life span and cropping pattern. The main aim of the disease management is to reduce the pathogen population to tolerable level. This is achieved by a variety of techniques or a judicial combination of physical, biological, host resistance and chemical control methods. As mulberry is perennial crop and nematode Meloidogyne incognita is endoparasitic in nature once it gets established in the garden it is difficult to eradicate. A single method alone cannot control the nematode effectively. Hence the disease is to be controlled by integrating different management techniques which involves different cultural, chemical and biological methods. In the present study realising the need of proper management of root knot nematode an integration of organic amendments like neem cake, biological methods using VAM and Verticillium chlamidosporium was done to find out their efficacy on six mulberry varieties viz:Tr10,DD,V1,RFS175,K2 and MS8.These six mulberry varieties were selected among twenty six mulberry varieties based on the study conducted for their degree of resistance/tolerance by using Egg mass Index and Root Gall Index after inoculating them with nematode juveniles as suggested by Hadisoegenda and Sasser (1982). In this study these six varieties have shown different degree of resistance like tolerant (Tr10), moderately tolerent (DD, V1), susceptible (RFS 175, K2) and MS8 (Highly susceptible).So for the present study varieties showing different degrees of tolerence and also popular varieties were selected.

\section{Materials And Methods:}

For this study the experimental plot was given randomized block design and four months old saplings of Tr10, DD, RFS175, V1, K2 and MS8 were planted with $60 \mathrm{~cm} \times 60 \mathrm{~cm}$ spacing. After three months of plantation each plant was inoculated with 1000 nematode juveniles /plant. The treatment was given by mixing $24 \mathrm{~kg}$ of neem cake + $200 \mathrm{~kg} \mathrm{FYM}+1 \mathrm{Kg}$ of bionema which is sufficient for 1000 plants and VAM at the rate of $100 \mathrm{~g} / \mathrm{plant}$ mixed in 20 $\mathrm{kg}$ of FYM. All these were applied in three split doses /year. 
Sixty days after application number of root galls/plant, and number of egg masses/g root weight were calculated and after the period of establishment, growth and yield parameters i.e. Total plant height, number of leaves/plant, weight of 100 leaves, leaf moisture percentage, leaf yield /ha/annum were calculated to find out the effect of integrated management by comparing infested with treated plots.

\section{Results And Disscussion}

In this study the following parameters were observed to know the effect of integration of bionema, neem cake and VAM on the management of root knot nematode Meloidogyne incognita in six mulberry varieties.

\section{The various parameters are as follows: \\ Nematode population:(Table 1)}

Number of egg masses/gm root weight: In these observations the variety Tr10 has shown 36.70 number of egg masses/ $\mathrm{g}$ root weight in control and the number was only 5.00 in treated. $86.45 \%$ of reduction was recorded which is highly significant compared to control. The DD variety has shown 47.66 number of egg masses in control against 7.40 in treated with a percentage of reduction of 84.47 in treated. In V1 the number of egg masses were 56.60 in control and treated 9.20 respectively with 83.63 percentage of reduction.

RFS 175 variety has shown 78.80 number of egg masses / $g$ root weight in control and 14.50 number of egg masses in treated with a percentage of reduction was 81.55 . In K2 variety the number of egg masses was 86.30 in control and it was 16.80 in treated. The percentage of reduction was 80.36. In MS8 variety the number of egg masses was 101.66 in control and 22.00 in treated. The percentage of reduction was 78.32.

In all these observations it was found that $\operatorname{Tr} 10$ has shown significant percentage of reduction (86.45) of egg masses/ $\mathrm{g}$ root weight compared to other varieties. It is followed by DD (84.55), V1 (83.84), RFS175 (81.43), K2 (80.06) and MS8 (78.32). Among all these varieties MS8 has shown less percentage of reduction.

Number of galls/plant: In these studies Tr10 has shown 135.80 number of galls /plant in control and 19.90 number of galls /plant in treated with a percentage of reduction of 85.30.

In DD variety the number of galls/plant in control was 166.36 and in treated 28.10. The percentage of reduction observed was 83.10. In V1 variety the number of galls/plant was 178.30 in control and 30.73 in treated. The percentage of reduction was 82.75. In RFS 175 the number of galls/plant in control and treated were 185.00 and 35.50 with a percentage reduction of 80.80 .

The number of galls/plant in K2 variety was 195.53 in control and 40.33 in treated with a percentage reduction of 79.37. In MS8 variety the number of galls/plant was 205.90 in control and 48.66 in treated. The percentage of reduction was 76.30 .

In all these varieties maximum percentage of reduction (85.30) was observed in $\operatorname{Tr} 10$ variety followed by DD (83.10), RFS175 (80.80), K2 (79.37) and MS8 (76.30). The minimum percentage of reduction was observed in MS8 (76.30). Significant reduction of egg masses and root galls (86.45 and 85.30) were observed in Tr10 variety. Significant difference was observed among varieties in all the parameters. Variations between control and treated also highly significant.

The results are in conformity with Singh et al (1971) who reported reduction of nematode population and increase in plant height and growth in tomato and okra.Jatala et al 1986 reported parasitization of Melodogyne incognita by Verticillium chlamidosporium, a biocontrol agent. The results are in conformity with Govindaiah (1994) who reported increased moisture percentage and yield when treated with neem cake. The results are also in conformity with Sharma (1999) who reported 23\%increase in leaf yield when treated with Verticillium chlamidosporium.Sankarnarayana et al reported that Verticillum chlamidosporium was found to be superior in the improvement of plant growth and parasitization of nematode eggs compared to other fungi. Sunder babu et al (1993) who reported improved plant growth in tomato raised on VAM. Asha John and Hebsy Bai (2004) reported improved plant growth and suppressed nematode population in brinjal when treated with VAM. Same results were observed in brinjal by Reddy et al (1993).Nematicidal activity of neem cake by secreting phenolic substances, nematode egg parasitization by Verticillium chlamidosporium played the major role in reducing the nematode population and also the organic manurial value of neem cake contributing in increasing plant growth and leaf yield. The reason in increased plant growth and suppressed nematode population in VAM treatment indicated the capability of the mycorrhizal fungi in establishing its superiority in the competition with nematodes for infection site in curbing the nematode entry and multiplication in the root.

So in conclusion it may be stated that integrated control is more effective in managing the root knot nematode Meloidogyne incognita. The varieties Tr10, DD, and V1 are found as nematode tolerant varieties which are also high yielders. These varieties can be grown in nematode infested areas. 


\section{References:}

[1]. Asha John and Hebsy Bai (2004). Evaluation of VAM for management of root knot nematode in Brinjal. Indian Journal of Nematology.34 (1)22-25.

[2]. Chanturia, N.N.Labahua, L.V. (1963). Soobsch Akad. Nauk Gruz SSR.32 (1), 141- 148

[3]. Govindaiah., Dandin, S.B., Giridhar, K. and Datta., R.K.(1994).Efficacy of different doses of neem oil cake on Meloidogyne incognita infecting mulberry. Sericologia, 34:717-721.

[4]. Hadisoegenda, W.W.and J.N.Sasser. (1982).Resistance of tomato, bean, southern pea and garden pea cultivars to root knot nematodes based on host susceptibility. Plant Dis.66:145-150.

[5]. Jatala,P.(1986).Biological control of plant parasitic nematodes.Ann.Rev.Phytopathology.24, 453-489 .

[6]. Saha, S.S.,Sinha Babu, S.P.and Sukul, M.C.(1983). The effect of nematodes infestation on mulberry plants and their effect on feeding silkworm Bombyx mori.L.Nematologica 29(4):463-467.

[7]. Sankaranarayanan, C., Hussaini, S.S., Sree Kumar, P.Prasad, R.D.(1997)Nematicidal effect of fungal filtrates against root knot nematodes.J.Biol.control. 11:34-37.

[8]. Sasser, J.N. (1979).Economic importance of Meloidogyne in tropical countries. In Root knot nematodes (Meloidogyne species) Systemic biology and control. Edited by Lamberti.F. and Taylor, C.E. Academic press.

[9]. Sharma, D.D. (1998).Eco friendly approach for management of Rootknot.IndianSilk,August,pp.15-16.

[10]. Shree,M.P.Boraiah,NarayanaGowda.S.N.(.1996).Nat.Sem.ProspProb.Sericulture, India, March 27-30, P 38

[11]. Shree,M.P.,Umesh kumar, N.N.(1991).Sericologia, 31(3),441-444.

[12]. Singh R.S., Sitaramaiah K.(1971) Control of root knot through organic and inorganic amendaments of soil, effect of oilcakes and saw dust. Indian.J.Mycol. and Plant pathology., 1, 20-29.

Table-I: Effect of Integrated control in the management of root knot nematode Melodogyne incognita in different mulberry varieties.

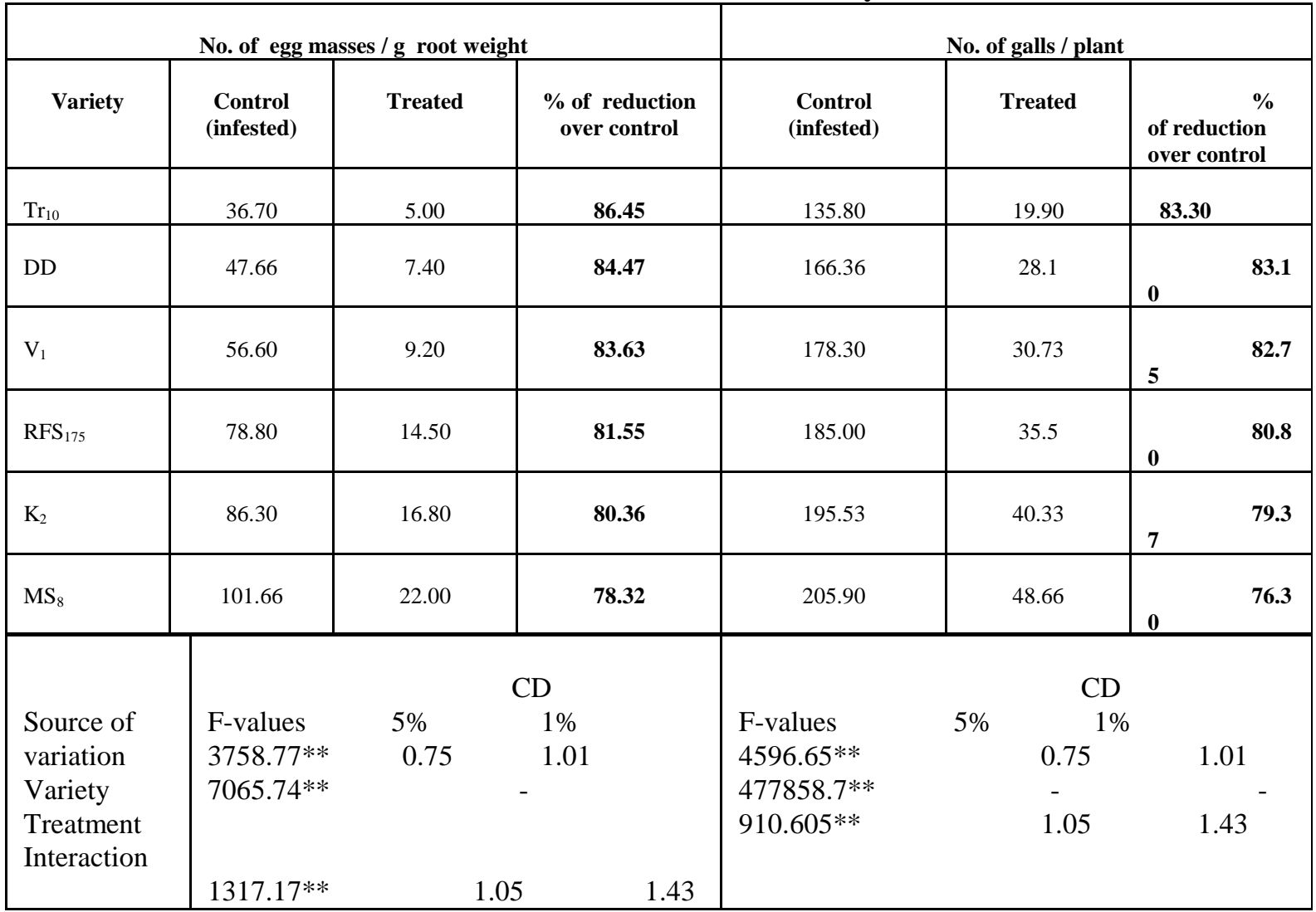

Note: $* *$ Highly significant at $1 \%$ level 
Fig.3: Effect of Integrated control in the management of root knot nematode Meloidogyne incognita in different mulberry varieties

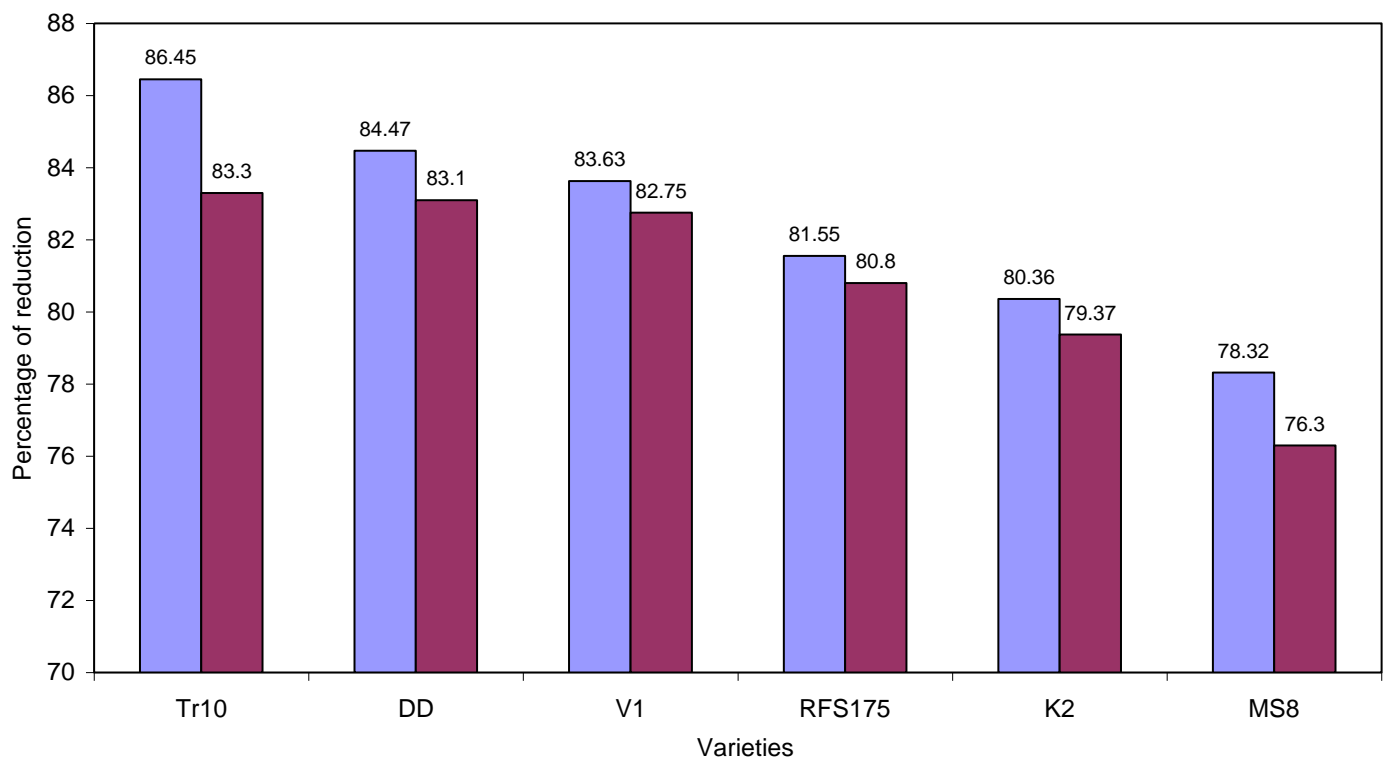

$\square$ No. of egg masses $\square$ No. of galls 